\title{
Distribution of Helicobacter pylori colonisation and associated gastric inflammatory changes: Difference between patients with duodenal and gastric ulcers
}

\author{
J A Louw, V Falck, C van Rensburg, J Zak, G Adams, I N Marks
}

\begin{abstract}
Aims-To determine the gastric distribution of Helicobacter pylori in patients with duodenal and gastric ulcers; and to examine the mucosal inflammatory response.

Methods-Patients with newly diagnosed, uncomplicated duodenal and gastric ulcers were endoscoped and two biopsy specimens each taken from the antrum and the body. Specimens were evaluated blind by one pathologist to determine $H$ pylori activity (scored $0-3$ ) and inflammatory changes (according to the Sydney classification).

Results-Adequate biopsy material was obtained from 40 and 44 patients with gastric and duodenal ulcers, respectively. Although antral colonisation with $H$ pylori was more common in the antrum of the latter, the organism was equally likely to be found in the body of both sets of patients; the density of colonisation was higher in those with gastric ulcers. Active gastritis and mucosal atrophy were more common in the body of those with gastric ulcers; intestinal metaplasia was also more common in the antrum of these patients.

Conclusions-Gastritis in patients with duodenal ulcers is mainly antral, but the incidence of gastric body colonisation with $H$ pylori seems to be the same in patients with either type of ulcer. There is, however, a significant difference in colonisation density. The cause and importance of this are not obvious and may be related to either host or organism factors.
\end{abstract}

(F Clin Pathol 1993;46:754-756)

Gastric Helicobacter pylori infection is strongly associated with duodenal ulcers and is also commonly found in association with gastric ulceration. ${ }^{1}$ It is, however, an extremely prevalent infection and has been found in up to $88 \%$ of patients studied in Africa, making it the most common bacterial infection in that continent. ${ }^{2}$ The organism is uniquely adapted to survive in the hostile gastric environment, and in fact seems able to colonise only gastric mucosa. This unique affinity for gastric mucosa is based on a specific receptor based mechanism, ${ }^{3}$ with the fibrillar haemagglutinin component of the organism acting as a "colonisation factor". "It has been postulated that in duodenal ulcer disease the organism is found mainly in the antrum, but not in the body or fundal mucosa, ${ }^{5}$ thereby leading to hypergastrinaemia and acid hypersecretion. Gastric ulceration, on the other hand, occurs against the background of a more widespread gastritic process, which may reflect a more extensive colonisation with $H$ pylori, or a difference in the immunological response of the gastric mucosa to the organism in these conditions.

\section{Methods}

Patients with newly diagnosed, uncomplicated gastric and duodenal ulceration were recruited from the gastroenterology outpatient services of the Groote Schuur and Tygerberg hospitals. All patients gave informed consent and the study was approved by the Ethics and Research Committee of the University of Cape Town.

All patients were subjected to a routine upper gastrointestinal endoscopy, using Xylocaine local anaesthetic with or without sedation with intravenous midazolam $2.5 \mathrm{mg}$. The ulcer site was defined as duodenal or gastric: pyloric channel ulcers were excluded from the study. Two biopsy specimens were taken from the antrum (less than $5 \mathrm{~cm}$ from the pylorus) and a further two from the posterior wall of the gastric body. Samples were preserved in formalin and evaluated by one pathologist, who had no prior knowledge of the ulcer diagnosis.

$H$ pylori activity was determined histologically using Giemsa staining. The density of colonisation was scored semiquantitatively as: 0 (organisms not found after a thorough search using Giemsa stained material); 1 (organisms found only after a thorough search of more than one high power field of Giemsa stained material); 2 (organisms found in every high power field, present only in crypts); and 3 (organism abundant in crypts and mucus layer).

Gastritis was classified according to the guidelines of the Sydney classification system. ${ }^{6}$ Only samples incorporating muscularis mucosae (full thickness mucosa) were evaluated for atrophy. Gastritis was assessed as being either "predominantly antral" or "pangastritis" according to the presence of chronic inflammatory changes found in the samples from body and antral mucosa.

Statistical analysis of categorical data was carried out using Fisher's exact and the Mantel-Haenszel $\chi^{2}$ tests and continuous 
Table 1 H pyloric activity

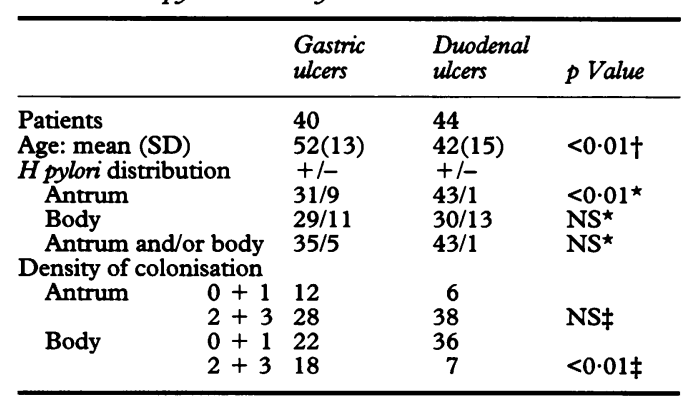

†Student's $t$ test; `Fisher's exact test; $\ddagger \chi^{2}$.

Table 2 Gastric morphology

\begin{tabular}{|c|c|c|c|}
\hline & $\begin{array}{l}\text { Gastric } \\
\text { ulcer }\end{array}$ & $\begin{array}{l}\text { Duodenal } \\
\text { ulcer }\end{array}$ & $p$ Value \\
\hline & $+1-$ & $+/-$ & \\
\hline $\begin{array}{l}\text { Neutrophul activity: } \\
\text { Antrum }\end{array}$ & $36 / 4$ & $40 / 4$ & $\mathrm{NS}^{\star}$ \\
\hline $\begin{array}{l}\text { Body } \\
\text { Mucosal atrophy: }\end{array}$ & $11 / 29$ & $4 / 40$ & $<0.05^{\star}$ \\
\hline $\begin{array}{l}\text { Antrum } \\
\text { Body } \\
\text { Intestinal metaplasia: }\end{array}$ & $\begin{array}{l}31 / 2 \\
8 / 31\end{array}$ & $\begin{array}{l}28 / 5 \\
0 / 43\end{array}$ & $\begin{array}{l}N^{\star} S^{\star} \\
<01^{\star}\end{array}$ \\
\hline $\begin{array}{l}\text { Antrum } \\
\text { Body }\end{array}$ & $\begin{array}{l}15 / 25 \\
3 / 37\end{array}$ & $\begin{array}{l}3 / 41 \\
0 / 44\end{array}$ & $\begin{array}{l}<0.001^{\star} \\
\mathrm{NS}^{\star}\end{array}$ \\
\hline
\end{tabular}

Student's $t$ test; `Fisher's exact test; $\ddagger \chi^{2}$.

variables were evaluated using Student's $t$ test, both using the EPISTAT statistical package. A $p$ value of $<0.05$ was considered significant.

\section{Results}

The results are summarised in tables 1-4.

Adequate antral and fundic biopsy specimens were obtained from 40 of 43 patients with gastric ulcer and from all 44 with duodenal ulcers. The patients with gastric ulcer were significantly older than the other group (mean (SD) age 52(13) years for gastric ulcers and 42(15) years for duodenal ulcers; $\mathrm{p}<0.01)$. The overall incidence of $H$ pylori infection was $88 \%(35 / 40)$ in gastric ulcer patients and $98 \%(43 / 44)$ in duodenal ulcer patients. This was not significant.

$H$ pylori was found more frequently in the antrum of patients with duodenal ulcers than in those with gastric ulcers: $43 / 44 v 31 / 40$; $\mathrm{p}<0.01$. The pattern of $H$ pylori colonisation

Table 3 Categorisation of histological characteristics, antrum

\begin{tabular}{|c|c|c|c|c|c|c|c|c|}
\hline & \multicolumn{4}{|c|}{ Duodenal ulcer } & \multicolumn{4}{|c|}{ Gastric ulcer } \\
\hline & 0 & 1 & 2 & 3 & 0 & 1 & 2 & 3 \\
\hline $\begin{array}{l}\text { Chronic inflammation } \\
\text { Neutrophil activity } \\
\text { H pylori density } \\
\text { Mucosal atrophy } \\
\text { Intestinal metaplasia }\end{array}$ & $\begin{array}{r}0 \\
4 \\
1 \\
5 \\
41\end{array}$ & $\begin{array}{r}3 \\
28 \\
5 \\
11 \\
1\end{array}$ & $\begin{array}{r}33 \\
11 \\
20 \\
16 \\
2\end{array}$ & $\begin{array}{r}8 \\
1 \\
18 \\
1 \\
0\end{array}$ & $\begin{array}{r}0 \\
4 \\
9 \\
2 \\
25\end{array}$ & $\begin{array}{r}2 \\
14 \\
3 \\
7 \\
5\end{array}$ & $\begin{array}{r}30 \\
21 \\
16 \\
21 \\
4\end{array}$ & $\begin{array}{r}8 \\
1 \\
12 \\
3 \\
6\end{array}$ \\
\hline
\end{tabular}

Table 4 Categorisation of histological characteristics, body

\begin{tabular}{|c|c|c|c|c|c|c|c|c|}
\hline & \multicolumn{4}{|c|}{ Duodenal ulcer } & \multicolumn{4}{|c|}{ Gastric ulcer } \\
\hline & 0 & 1 & 2 & 3 & 0 & 1 & 2 & 3 \\
\hline $\begin{array}{l}\text { Chronic inflammation } \\
\text { Neutrophil activity } \\
H \text { pylori density } \\
\text { Mucosal atrophy } \\
\text { Intestinal metaplasia }\end{array}$ & $\begin{array}{l}25 \\
40 \\
13 \\
43 \\
44\end{array}$ & $\begin{array}{r}18 \\
2 \\
23 \\
0 \\
0\end{array}$ & $\begin{array}{l}1 \\
2 \\
7 \\
0 \\
0\end{array}$ & $\begin{array}{l}0 \\
0 \\
0 \\
0 \\
0\end{array}$ & $\begin{array}{l}11 \\
29 \\
11 \\
31 \\
37\end{array}$ & $\begin{array}{r}19 \\
6 \\
11 \\
2 \\
2\end{array}$ & $\begin{array}{r}9 \\
5 \\
14 \\
5 \\
0\end{array}$ & $\begin{array}{l}1 \\
0 \\
4 \\
1 \\
1\end{array}$ \\
\hline
\end{tabular}

also differed in the two groups of patients. Antral colonisation was more common in patients with duodenal ulcer than body colonisation- $43 / 44$ positive in the antrum, $30 / 43$ positive in the body; $p<0.001$. No difference was found in the distribution of the organism in patients with gastric ulcers$31 / 40$ (antrum) $v 29 / 40$ (body).

The pattern of distribution differed, but the incidence of body colonisation did not differ in both groups of patients-30 of 43 patients with duodenal ulcer were colonised in the body of the stomach, compared with 29 of 40 with gastric ulcers. There was, however, a significant difference in the density of body colonisation, with the group with gastric ulcers containing significantly more subjects in the 2 and 3 density categories (18 of 29 with gastric ulcers $v$ seven of 30 with duodenal ulcers; $\mathrm{p}<0.01$ ).

Differences were noted in the gastritic characteristics of the two ulcer groups (tables 2-4). Active gastritis (neutrophil activity) was found more often in the body of patients with gastric ulcers and atrophy was also more common (eight of $39 v 0$ of 43; p < 0.01). The incidence of antral intestinal metaplasia also differed noticeably between the groups15 of the 40 patients with gastric ulcers showed evidence of antral intestinal metaplasia, compared with three of 44 patients with duodenal ulcers; $p<0.001$. When patients were stratified into three arbitrarily chosen age groups (15-40 years, 40-60 years, and over 60 years), and the data analysed by the Mantel-Haenszel $\chi^{2}$ test controlling for age, the differences in prevalence of both antral intestinal metaplasia $(p<0.01)$ and body atrophy $(p<0.05)$ remained significant, although less so, and only marginal in the case of body atrophy.

The gastritic process tended to be predominantly antral in duodenal ulceration: in gastric ulceration a pangastritic process was more common. The gastritis was deemed to be predominantly antral in 39 of the patients with duodenal ulcers, compared with 23 of those with gastric ulcers, and pangastritic in five of the former and 17 of the latter; $\mathrm{p}<0.01$.

\section{Discussion}

This study confirms that the gastritis in duodenal ulcer disease is predominantly antral in nature, while it is more widespread in gastric ulceration. The finding that gastric ulcer disease is more commonly associated with antral intestinal metaplasia is consistent with the findings of earlier studies, ${ }^{78}$ but seems to be at variance with a recent study, ${ }^{9}$ in which this difference was not found when the data were analysed controlling for age.

The almost identical incidence of $H$ pylori in the body of the stomach in the duodenal and gastric ulcer disease groups may be construed as contradicting the established view that patients with duodenal ulcers have fundal "sparing" of $H$ pylori colonisation. ${ }^{5}$ The fundal inflammatory morphological changes 
were, however, associated with a significantly higher colonisation density in the group with gastric ulcers. In this regard, the findings of our study agree with earlier reports suggesting a correlation between the magnitude of the inflammatory response and the density and depth of $H$ pylori colonisation, ${ }^{10-12}$ rather than the presence of $H$ pylori itself.

Several factors may be important in determining the difference in the colonisation density gradient in duodenal and gastric ulcers. Firstly, this may merely reflect the duration or chronicity of the infection. This seems to be borne out by the finding of a significantly older mean age, as well as the presence of markers for chronic gastritis (atrophy and intestinal metaplasia) in the gastric ulcer group. The relation of age to the chronicity of gastritis is not simple, however, and the duration of the gastritis may be better assessed by the chronicity of symptoms, an approach used in earlier studies. ${ }^{8}$ Studies on the natural history of duodenal ulcer associated type B gastritis have claimed that the inflammatory changes do not progress to include the body or fundus, whereas the gastritis in patients with gastric ulcer or gastritis without peptic ulcer disease is progressive. ${ }^{13-14}$ It thus seems unlikely, based on current data, that $H$ pylori infection spreads proximally up the body of the stomach from the antrum in patients with duodenal ulcers. Suitably designed longitudinal studies, however, should address this important question as the controversial phenomenon of duodenal ulcer "burnout", first suggested by Fry, ${ }^{15}$ may be explained by proximal spread of the gastritic process, with resultant hypochlorhydria.

Secondly, as gastric colonisation with $H$ pylori seems to be mediated by specific $H$ pylori colonisation factors for gastric glycerolipid receptors, ${ }^{3}$ it is conceivable that either the affinity of the organism's colonisation factor may vary, or that the distribution of these glycerolipid receptors in patients may differ, giving rise to either organism or host differences in colonisation patterns and resulting in, or associated with, different gastroduodenal diseases. There is some evidence that strain differences may exist between organisms found in different gastroduodenal disease states: Crabtree et al have shown a strong association between the presence of a strain of $H$ pylori containing a 120 kilodalton membrane protein and duodenal ulcer disease. ${ }^{16}$ There is at present no information to suggest that the distribution of the glyceroreceptor differs among individuals.

Finally, patients with duodenal ulcers may be resistant to colonisation of the oxyntic mucosa by $H$ pylori by virtue of the increased acid secretion found in this group of patients, which in turn may protect the oxyntic mucosa from bacterial colonisation. ${ }^{17}$

In summary, this study confirms the established finding with regard to the distribution of gastritis in duodenal and gastric ulcer disease. It shows, however, that in the population studied, colonisation of the gastric body by $H$ pylori is equally common in gastric and duodenal ulcer disease, but that the density of colonisation and the inflammatory changes are less noticeable in patients with duodenal ulcer, as is the case in non-ulcer subjects with type $B$ gastritis. ${ }^{18}$ These differences seem to be linked to differences in colonisation density, but other host or organism factors could be relevant.

1 Moss S, Calam J. Helicobacter pylori and peptic ulcers: the present position. Gut 1992;33:289-92.

2 Holcombe C, Omotara BA, Eldridge J, Jones DM. H pylori, the most common bacterial infection in Africa: a pylori, the mostical survey. Am $¥$ Gastroenterol 1992;87: 28-30.

3 Lingwood CA, Pellizzari A, Law H, Sherman P, Drumm B. Gastric glycerolipid as a receptor for Campylobacter pylori. Lancet 1989;ii:238-41.

4 Evans DG, Evans DJ, Moulds J, Graham DY. N-acetylneuraminallactose-binding fibrillar hemagglutinin of Campylobacter pylori: a putative colonization facto antigen. Infect Immun 1989;56:2896-906.

5 Levi S, Haddad G, Ghosh P, Beardshall K, Playford R, Calam J. Campylobacter pylori and duodenal ulcers: the gastrin link. Lancet 1989;i:1167-8.

6 Misiewiecz JJ, Tytgat GNJ, Goodwin CS, et al. The Sydney system: a new classification of gastritis. In: Working Party Reports of the World Congresses of Gastroenterology, 26-31 August 1990, Sydney, Australia. Gastroenterology, 26-31 August 1990, Sydney, Australia.

7 Schrager J, Spink R, Mitra S. The antrum in patients with duodenal and gastric ulcers. Gut 1967;8:497-508.

8 Gear MWL, Truelove SC, Whitehead R. Gastric ulcer and gastritis. Gut 1971;12:639-45.

9 Sobala GM, Axon ATR, Dixon MF. Morphology of chronic antral gastritis: relationship to age, Helicobacter pylori status and peptic ulceration. Eur $\mathcal{f}$ Gastroenterol Hepatol 1992;4:825-9.

10 Bayerdorffer E, Lehn N, Hatz R, Mannes GA Sauerbruch $\mathrm{T}$, Stolte $\mathrm{M}$. Difference in expression of Helicobacter pylori gastritis in antrum and body. Gastroenterology 1992;102:1575-82.

11 Neri M, Susi D, Bovani I, Cuccurullo F. Histological evidence of disease activity in Helicobacter pylori gastriti depends on the depth of mucosal invasion. Gastroenterology 1992;102:A135.

12 Alam K, Schubert TT, Bologna SD, Ma CK. Increased density of Helicobacter pylori on antral biopsy is associated with severity of acute and chronic inflammation and likelihood of duodenal ulceration. $A m, 7$ Gastroenterol 1992;87:424-8.

13 Kekki M, Sipponen P, Siurala M. Progression of antral and body gastritis in patients with active and healed and body gastritis in patients with active and healed 1984;19:382-8.

14 Tatsuta $M$, Iishi $H$, Okuda $S$. Location of peptic ulcers in relation to antral and fundal gastritis by chromoendoscopic follow-up examinations. Dig Dis Sci 1986;31: $7-11$.

15 Fry J. Peptic ulcer: a profile. $\mathrm{Br}$ Med f 1964;2:809-12.

16 Crabtree JE, Taylor JD, Wyatt JL, et al. Mucosal IGA recognition of Helicobacter pylori $120 \mathrm{kDa}$ protein, peric ulceration and p38:332-5.

17 Graham DY. Campylobacter pylori and duodenal ulcer disease. Gastroenterology 1989;96:615-25.

18 Kimura $\mathrm{K}$. Chronological transition of the fundic-pyloric border determined by stepwise biopsies of the lesser and greater curvatures of the stomach. Gastroenterology 1972; 63:584-92. 